This item was submitted to Loughborough's Research Repository by the author.

Items in Figshare are protected by copyright, with all rights reserved, unless otherwise indicated.

\title{
Conversational assessment in memory clinic encounters: interactional profiling for differentiating dementia from functional memory disorders
}

\section{PLEASE CITE THE PUBLISHED VERSION}

http://dx.doi.org/10.1080/13607863.2015.1021753

\section{PUBLISHER}

(C) Taylor and Francis

\section{VERSION}

AM (Accepted Manuscript)

\section{PUBLISHER STATEMENT}

This work is made available according to the conditions of the Creative Commons Attribution-NonCommercialNoDerivatives 4.0 International (CC BY-NC-ND 4.0) licence. Full details of this licence are available at: https://creativecommons.org/licenses/by-nc-nd/4.0/

\section{LICENCE}

CC BY-NC-ND 4.0

\section{REPOSITORY RECORD}

Jones, Danielle, Paul Drew, Christopher Elsey, Daniel Blackburn, Sarah Wakefield, Kirsty Harkness, and Markus Reuber. 2019. "Conversational Assessment in Memory Clinic Encounters: Interactional Profiling for Differentiating Dementia from Functional Memory Disorders”. figshare. https://hdl.handle.net/2134/17153. 


\section{Conversational assessment in memory clinic encounters: interactional profiling for differentiating dementia from functional memory disorders}

Danielle Jones*, Paul Drew, Chris Elsey, Daniel Blackburn, Sarah Wakefield, Kirsty Harkness, Markus Reuber

Bradford Dementia Group, University of Bradford, Bradford, UK; Department of Social Sciences, Loughborough University, Loughborough, UK; Department of Social Sciences, Loughborough University, Loughborough, UK; Academic Neurology Unit, University of Sheffield, Sheffield, UK; Sheffield Institute for Translational Neuroscience (SITraN), University of Sheffield, Sheffield, UK

Corresponding Author: Danielle Jones, Bradford Dementia Group, Faculty of Health Studies, University of Bradford, Bradford, BD7 1DP. Telephone: 01274 236469 Email: d.k.jones1@bradford.ac.uk

Paul Drew, Department of Social Sciences, Loughborough University, Epinal Way, Leicestershire, LE11 3TU. Telephone: 01509223365 Email: p.drew@lboro.ac.uk

Chris Elsey, Department of Social Sciences, Loughborough University, Epinal Way, Leicestershire, LE11 3TU. Email: C.Elsey@lboro.ac.uk

Daniel Blackburn, Sheffield Institute for Translational Neuroscience (SITraN), University of Sheffield, 385A Glossop Road, Sheffield, S10 2HQ. Telephone: 01142222267 Email: d.blackburn@sheffield.ac.uk

Sarah Wakefield, Department of Neuroscience, Medical School, University of Sheffield, Sheffield, S10 2TN. Email: s.wakefield@sheffield.ac.uk

Kirsty Harkness, Department of Neurology, Royal Hallamshire Hospital, Glossop Road, Sheffield, S10 2JF. Email: kirsty.harkness@sth.nhs.uk

Markus Reuber, Academic Neurology Unit, University of Sheffield, Royal Hallamshire Hospital, Glossop Road, Sheffield, S10 2JF. Telephone: 01142268688 Email: markus.reuber@sth.nhs.uk

Acknowledgements: This article presents independent research funded by the National Institute for Health Research (NIHR) under its Research for Patient Benefit (RfPB) Programme (Grant Reference Number PB-PG-0211-24079). The views expressed are those of the author(s) and not necessarily those of the NHS, the NIHR or the Department of Health.

Forthcoming in Aging \& Mental Health 


\title{
Conversational assessment in memory clinic encounters: interactional profiling for differentiating dementia from functional memory disorders
}

\begin{abstract}
Objectives: In the UK dementia is under-diagnosed, there is limited access to specialist memory clinics, and many of the patients referred to such clinics are ultimately found to have functional (nonprogressive) memory disorders (FMD), rather than a neurodegenerative disorder. Government initiatives on 'timely diagnosis' aim to improve the rate and quality of diagnosis for those with dementia. This study seeks to improve the screening and diagnostic process by analysing communication between clinicians and patients during initial specialist clinic visits. Establishing differential conversational profiles could help the timely differential diagnosis of memory complaints.
\end{abstract}

Method: This study is based on video- and audio recordings of 25 initial consultations between neurologists and patients referred to a UK memory clinic. Conversation analysis was used explore recurrent communicative practices associated with each diagnostic group..

Results: Two discrete conversational profiles began to emerge, to help differentiate between patients with dementia and functional memory complaints, based on 1) whether the patient is able to answer questions about personal information; 2) whether they can display working memory in interaction; 3) whether they are able to respond to compound questions; 4) the time taken to respond to questions; and 5) the level of detail they offer when providing an account of their memory failure experiences.

Conclusion: The distinctive conversational profiles observed in patients with functional memory complaints on the one hand and neurodegenerative memory conditions on the other suggest that conversational profiling can support the differential diagnosis of functional and neurodegenerative memory disorders.

Keywords: Dementia, functional memory disorder, conversation analysis, differential diagnosis, interaction,

\section{Introduction}

There has been a sharp increase in the number of people referred to and attending secondary care memory clinics. The number of people assessed by memory clinics has risen four-fold since 2010 (Royal College of Psychiatrists, 2013). These referral rates are expected to rise further as the UK government introduce incentives for practitioners to screen for dementia (DOH, CQUIN 2012; NHS, DES 2013). The increase in referrals risks overwhelming memory clinics and other specialist services (such as neurology, gerontology and old age psychiatry). Specialist memory services are already under pressure in many areas of the United Kingdom and there is great national variation in memory clinic service provision and the time it takes for people to be diagnosed. The rate of people with dementia carrying a formal diagnosis is currently only $48 \%$ in England and varies from $32 \%$ in the worst performing areas to $75 \%$ in the best 
(Alzheimer's Society, 2014). The government initiatives on 'timely diagnosis' aim to close the 'dementia gap' and increase the percentage of people with dementia receiving a diagnosis by two thirds by 2015 .

Whilst demographic and sociological factors as well as government policies have led to a dramatic increase in the number of referrals to specialist memory services, this increased activity has done little to close the dementia diagnosis gap (Larner, 2014). One important reason for this is that an increasing number of the patients with concerns about their memory show no signs of a neurodegenerative disorder. In fact, patients in this group have recently constituted over $50 \%$ of those attending neurology-led memory clinics in Sheffield, Cambridge and the rest of the UK (Blackburn, Bell, Wakefield, Harkness, Rittman et al., 2015). Previous studies from other countries demonstrate that the phenomenon of nonprogressive memory problems, which may be summarised under the term functional memory disorder (FMD), is not unique to the UK (Høgh, Waldermar, Knudsen, Bruhn, Mortensen et al., 1999; Verhey, Jolles, Ponds, \& Vreeling, 1993). A careful longitudinal study in which patients diagnosed with FMD by experts were followed up and re-examined after an interval suggest that memory problems in FMD do not progress and that the FMD diagnosis rarely has to be changed to one of dementia (Schmidtke, Pohlmann \& Metternich, 2008).

At present the clinical differentiation between a form of dementia and FMD is often the result of a protracted process, and further research is needed to establish reliable biological markers to improve the differential clinical definitions and diagnostic accuracy between progressive neurodegenerative disorders and 'functional' memory concerns (Knopman, DeKosky, Cummings, Chui, Corey-Bloom et al., 2001). The diagnosis is based on a clinician's interpretation of the history given by a patient and their companion, complemented by brain scanning (Magnetic Resonance Imaging, MRI or Computerised tomography, CT) and extensive neuropsychological testing. In uncertain cases, the diagnostic process will involve a re-examination and investigation of the patient after an interval of six to twelve months. This diagnostic process requires considerable expertise, is costly and time-consuming and cannot be offered to all people complaining of memory problems. A 'suspended' diagnosis is likely to cause significant anxiety and unlikely to improve the condition of patients with functional memory complaints; and patients, as well as their family carers, often find the lengthy process of extensive testing distressing (Lai, Hawkins, Gross \& Karlawish, 2008; Gibson \& Anderson, 2011). Simpler and shorter neuropsychological screening instruments can help alert clinicians to the presence of cognitive problems but lack specificity and are only of modest diagnostic value without additional clinical data (Boustani, Callahan, Unverzagt, Austrom, Perkins et al., 2005; Hesler, Bronner, Etgen, Ander, Forstl et al., 2014).

To address the problems associated with the current diagnostic process, medical practitioners are increasingly searching for new approaches that improve and speed up the process, reduce the distress to patients and place less emphasis on extensive and expensive formal testing. Interactional diagnostic pointers in the conversation in which patients describe their memory complaints to the doctor could provide the sort of valuable and easily obtainable additional information which, combined with simple cognitive screening tests, would allow 
clinicians and GPs to make more timely and accurate decisions about whom to refer for more detailed investigation.

This paper reports the findings of a qualitative, in depth analysis of the conversations between neurologists and patients recruited from a specialist neurology-led memory clinic. The aim of this research is to assist in the diagnosis of memory complaints, particularly to assist in the diagnostic differentiation between dementia from those associated with functional memory disorder (FMD). Through careful, detailed analysis of patients' communication in their first encounters with neurologists, our research strategy is to identify features of patients' talk and interaction patterns that have the potential to help clinicians differentiate between people presenting with a progressive dementia and those presenting with other non-progressive memory complaints. A further goal is thereby to reduce the extent to which patients undergo what may be unnecessary and distressing further neuropsychological testing. Anecdotal evidence from conversations with neurologists suggests that specialist practitioners will often form a working diagnosis within the first five minutes of the opening of the consultation. This research seeks to provide the conversational evidence underpinning such clinical assessments, and explores whether interactional or linguistic features can be identified and described which could help with the diagnostic process when patients present with memory complaints.

Methods

\section{Study design \& subjects}

Video- and audio recording of 25 initial consultations between

neurologists and patients referred to the specialist neurology-led memory clinic at the Royal Hallamshire Hospital (Sheffield, UK) were collected between October 2012 and August 2014. Patients were referred to the clinic by primary care general practitioners (GPs), neurologists and other secondary services such as psychiatry. Patients lacking capacity were not recruited into this study. 9 of the patients were male and 16 female. The patients' ages ranged from 47 to 77 (median age for those with dementia $=61$, for those with FMD $=60$ ). Patients were seen by one of 3 consultant neurologists with a special interest in memory disorders. Patients were routinely encouraged to bring to the appointment a family member, friend or carer. A 'gold standard' clinical diagnosis was made by a consultant neurologist with a special interest in memory disorders. This diagnosis was made on the basis of a patient's initial visit, including screening with the Addenbrooke's Cognitive Examination (ACE-R), and subsequent detailed neuropsychological test battery and magnetic resonance imaging (MRI) of the brain. Transcripts of the 25 conversations were subjected to interactional profiling using Conversation Analysis (CA). 9 of the patients included received a diagnosis of a neurodegenerative memory disorder (average ACE-R score $56 / 100$, range from 28-80) and 16 were diagnosed with a functional (nonprogressive) memory complaint (average ACE-R score 93/100 range from 8599) (for a definition of FMD see Blackburn, Wakefield, Shanks Harkness, Reuber et al., 2014, Schmidtke et al., 2008; Schmidtke \& Metternich, 2009). This study represents an initial analysis of data from on-going research using CA in the memory clinic to identify potential interactional and linguistic diagnostic 
pointers. At the time of writing, recruitment to the study and further analysis were ongoing.

\section{Data analysis}

Recordings were transcribed in considerable detail, using CA transcription conventions (Jefferson, 1983, 2004; see Appendix 1). In transcribing the data, all names of people, places and other potentially identifying information have been pseudonymised.

The qualitative method of CA was used to analyse the data (for a summary see Drew, 2001 \& 2005; Sidnell, 2010). This micro-analytic approach has been applied successfully in primary care services to examine the organization of medical communication (for a review Heritage \& Stivers, 1999; Stivers, 2002; Heritage \& Maynard, 2006; Heritage et al, 2007). More recently, research has been conducted in secondary care services revealing medical communication to be a powerful diagnostic tool for practitioners (Schwabe, Howell \& Reuber, 2007; Robson, Drew Walker \& Reuber, 2012). Most notably, this study follows the design of research conducted in the seizure clinic at the Royal Hallamshire Hospital in Sheffield, UK, by a team that has used CA methodology in the differential diagnosis of seizure disorders. This research identified diagnostically relevant linguistic, topical and interactional features that aided clinicians to differentiate between a diagnosis of epileptic and nonepileptic seizures. Furthermore, a prospective multi-rater study has confirmed the diagnostic potential of these conversational profiles in the seizure clinic setting. By using a diagnostic scoring aid (DSA) to convert qualitative assessments into a numeric score, analysts blinded to diagnosis predicted $85 \%$ of diagnoses correctly. The video-EEG recording of typical attacks ultimately proved all diagnoses (see Reuber, Monzoni, Sharrack \& Plug, 2009). These interdisciplinary collaborations between clinicians and conversation analysts support an applied approach whereby research findings inform medical practice (Reuber et al, 2009; Ekberg, McDermott, Moynihan, Brindle, Little et al., 2014).

This paper will present only a small number of extracts, comprising only short communicative exchanges, but they exemplify larger patterns in the data. This is a practice routinely used in CA research to evidence the findings.

\section{Ethics}

The patients recruited received written information about the study prior to their appointment date and had the opportunity to ask questions of a member of the research team (not the doctor they had come to see) prior to their initial appointment in the memory clinic. All participants gave written informed consent to participate and were informed that they could withdraw from the study at any time. Patients lacking capacity to consent were excluded from the study. The study was approved by NRES Committee Yorkshire \& The Humber South Yorkshire.

\section{Results}

The initial history-taking phase of the encounters, which formed the basis of this analysis, lasted between 7 minutes and 28 seconds and 32 minutes and 29 seconds. 9 of the patients were male, 16 were female. The patient's age ranged 
from 47 to 77 . Of the 25 encounters included in this initial analysis (on the basis of these being the first 25 cases for which 'gold standard' diagnoses were available), 11 were dyadic (interactions between the neurologist and the patient) and 14 were triadic (involving interactions between a doctor, a patient and a companion). None of the patients who ultimately received a diagnosis of a progressive neurodegenerative memory problem attended the clinic alone, whereas 11 of the 16 patients with FMD came unaccompanied. This paper focuses solely on dyadic features of these interactions (a further report of triadic features of these interactions is under review; Elsey, Drew, Jones, Blackburn, Wakefield et al., 2014). Our initial analysis has identified five features that could contribute to a differential diagnostic conversational profile of patients presenting with dementia or FMD. These features are: 1) whether the patient is able to answer questions about personal information (for example "how old are you?' or 'where do you live?'); 2) whether they can display working memory in interaction; 3) whether they are able to respond to compound questions; 4) time taken to respond to questions; and 5) the level of detail they offer when providing an account of their memory failure experiences.

\section{Responding to questions about personal information}

Routinely, at the beginning of the consultations, neurologists ask patients a series of questions. These questions are designed to seek personal information from the patient, for example how old they are or where they live. The first two extracts demonstrate contrasting cases in which the neurologist is asking the patient's age. The first patient (Extract 1 ) subsequently received a medical diagnosis of FMD, the second one of dementia (Extract 2).

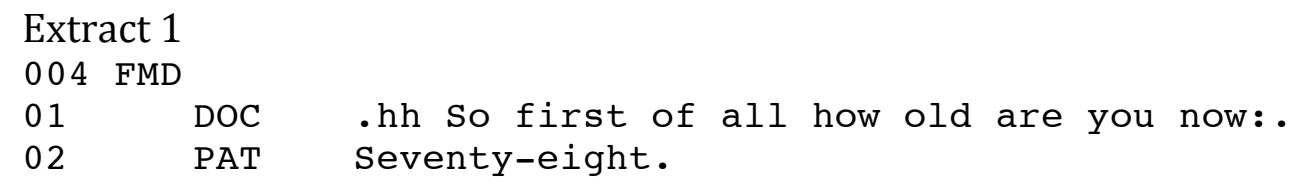




$\begin{array}{lll}20 & \text { PAT } & \text { Well I wa:s mu hu hu } \\ 21 & & (3.0) \\ 22 & \text { PAT } & \text { No. It's gone. } \\ 23 & & (0.8) \\ 24 & \text { DOC } & \text { Oka:y. S[O } \\ 25 & \text { COM } & \text { [Sixty nine. }\end{array}$

The first extract (1) is typical of patients with FMD in that they are able to produce the information required by the neurologist quickly and unproblematically. The second extract (2) illustrates how patients with dementia regularly have difficulty recalling personal information (in this case the patient's wife intercedes in lines 12 and 15 to try to prompt the patient to answer and eventually in line 25 answers on his behalf). A person's ability to respond contiguously and accurately to questions seeking personal information such as their age differentiates those with FMD, from those with dementia (who often struggle to produce the correct information).

\section{Working memory in interaction}

The second feature also relates to a patient's memory functionality. Working memory is one area of cognition examined in neuropsychological tests (such as the ACE-R). This aspect of cognitive functionality can also be displayed and assessed in interaction during the history taking conversation. The patient in Extract 3 (diagnosed with FMD) is able to display memory in the interaction itself.

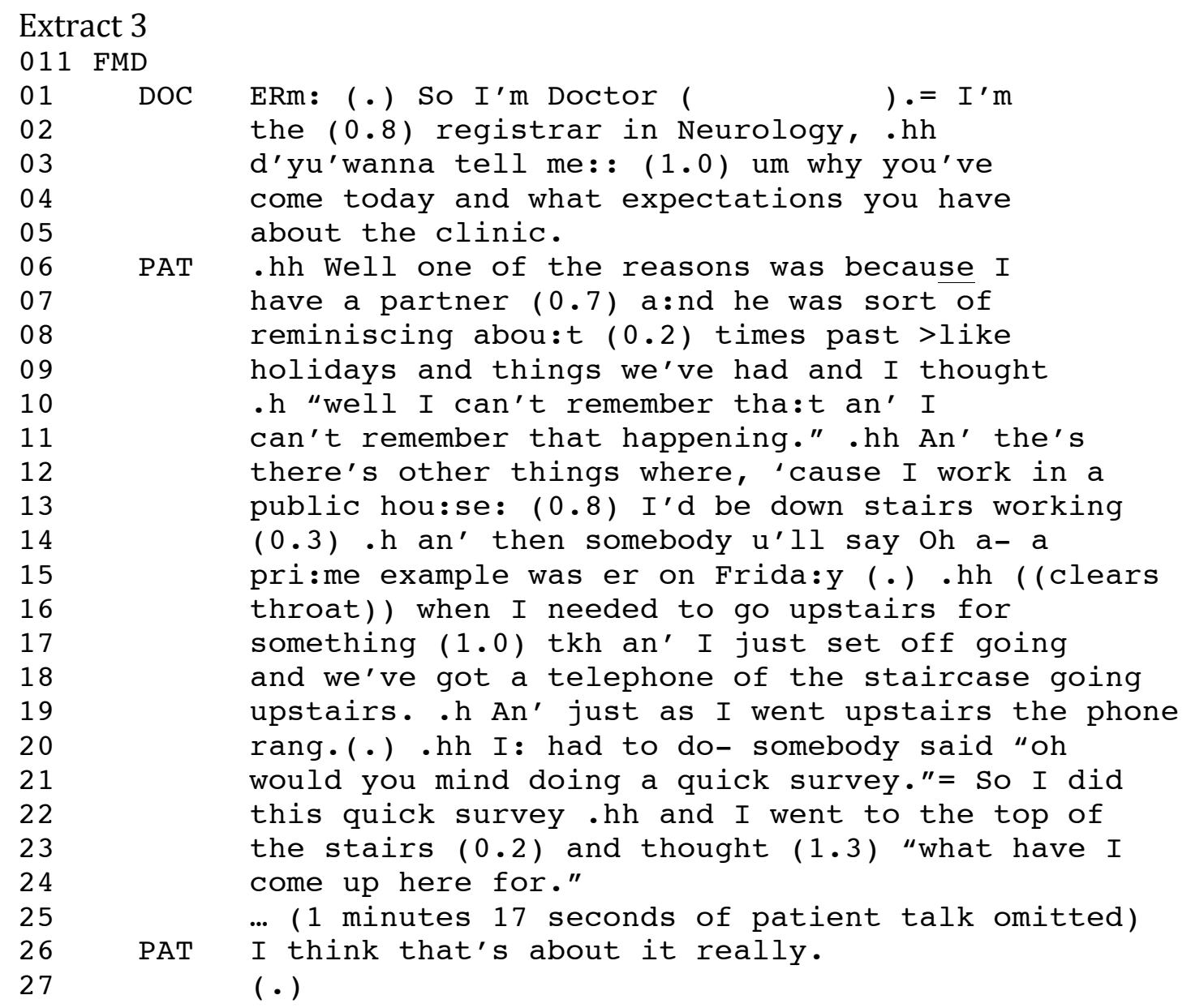




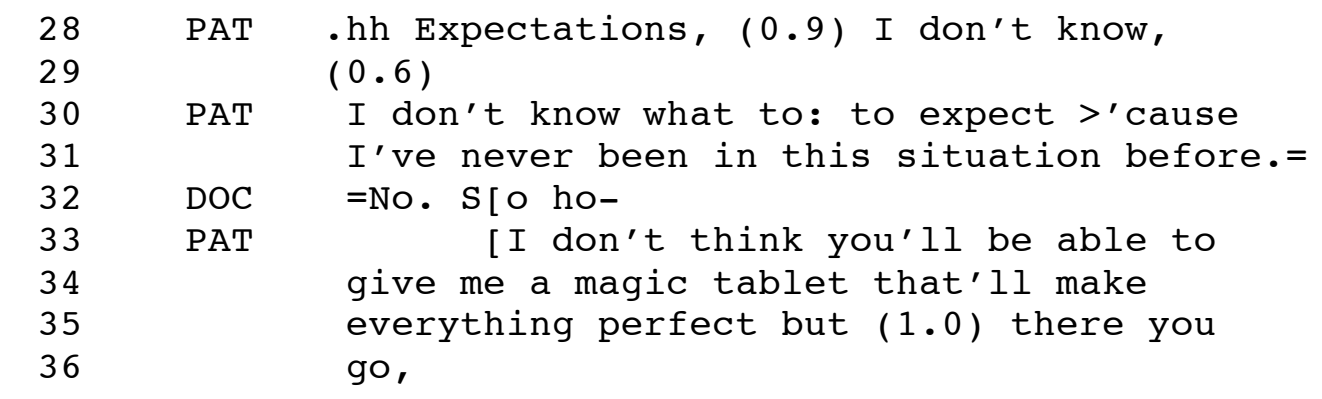

The neurologist asks the patient a question made up of two parts requiring two separate answers. The first, 'd'yu'wanna tell me why you've come today' (lines 34) pragmatically requires the patient to inform the neurologist about the reason for their attendance at the clinic; and the second, '(d'yu'wanna tell me) what expectations you have about the clinic' (lines 4-5). The patient proceeds with an extended telling, in great detail, about his memory failure experiences. Prefacing the telling with 'Well one of the reasons was...' attends to the first part of the neurologist's question. Having fully answered that questions after 2.5 minutes (1:17mins omitted from the transcript) the patient is perfectly able to retrieve the second part of the question and answer it, 'Expectations. I don't know' (line 28). This demonstrates that the patient is aware of the requirements of both the questions, can process them and respond accordingly, and can display through interaction his cognitive functioning with regards to working memory. Patients with FMD not only display working memory in relation to what the other has said in the consultation (as seen in Extract 3,recalling the neurologist's prior talk), but also when recalling and repeating information they themselves have previously mentioned. People with FMD do additional interactional work, marking their self-repetitive talk with 'like I said' or 'as I say', which orients to their awareness of their talk as being repetitive and displays their working memory functionality in the interaction (see Extract 4).

Extract 4

028 FMD

\begin{tabular}{|c|c|c|}
\hline $\begin{array}{l}01 \\
02 \\
03\end{array}$ & PAT & $\begin{array}{l}\text {.hh I seem to get- I- I do tend to get } \\
\text { mi:graines which is: li:ght induced. } \\
(0.4)\end{array}$ \\
\hline 04 & PAT & If I get a flashing light or:, \\
\hline 05 & $\mathrm{COM}$ & ${ }^{\circ}$ You've always had that [thoug]h. ${ }^{\circ}$ \\
\hline 06 & $\mathrm{PAT}$ & [Yeah.] \\
\hline $\begin{array}{l}07 \\
08\end{array}$ & DOC & $\begin{array}{l}\text { Can you take me through a typ- typical } \\
\text { mi:graine:. (.) for you, }\end{array}$ \\
\hline $\begin{array}{l}09 \\
10 \\
11\end{array}$ & PAT & $\begin{array}{l}\text {.h For me it's: u- >as I say< it's usually } \\
\text { li:ght induced a:nd it always starts with } \\
\text { flashing li:ghts: in my right eye. }\end{array}$ \\
\hline
\end{tabular}

Here the patient informs the neurologist that he suffers from light induced migraines (lines 1-2), adding that he experiences a 'flashing light' (line 4). The neurologist asks for further information about the patients migraines (lines 6-8), in response to which the patient repeats what he had previously told the neurologist about his migraine being 'light induced' and their being associated with 'flashing lights' (lines 9-11). However he prefaces this repetition with 'as I say' (line 9) to mark his self-repetition and to display that the information which 
will proceed has been voiced by him previously. This interactional resource, which displays working memory, appears as a recurrent feature in the consultations with patients with FMD and contributes to their conversational profile.

Unlike patients with FMD, those with dementia are often unable to display memory in this way in their consultations. They are often unable to retain information about what has been said even a few seconds earlier in the interaction, either by themselves or by the neurologist. When repeating themselves, they do not indicate that they are aware of their repetitions - that is, they do not preface their repetitions with such markers of awareness as 'As is said...'. This absence of marked self-repetitions is therefore a part of the conversational profile of those with dementia. Repeated information is often delivered as if for the first time (Jones, 2013). These 'second first-time tellings' are not marked using prefaces such as 'as I said'. Neurologists often indicate that they are aware that the patients are repeating themselves. Extract 5 is an example of an unmarked repetition or a 'second first-time telling' where a person with dementia is repeating information previously told to the neurologist as if for the first time. This provides interactional evidence that their working memory is compromised.

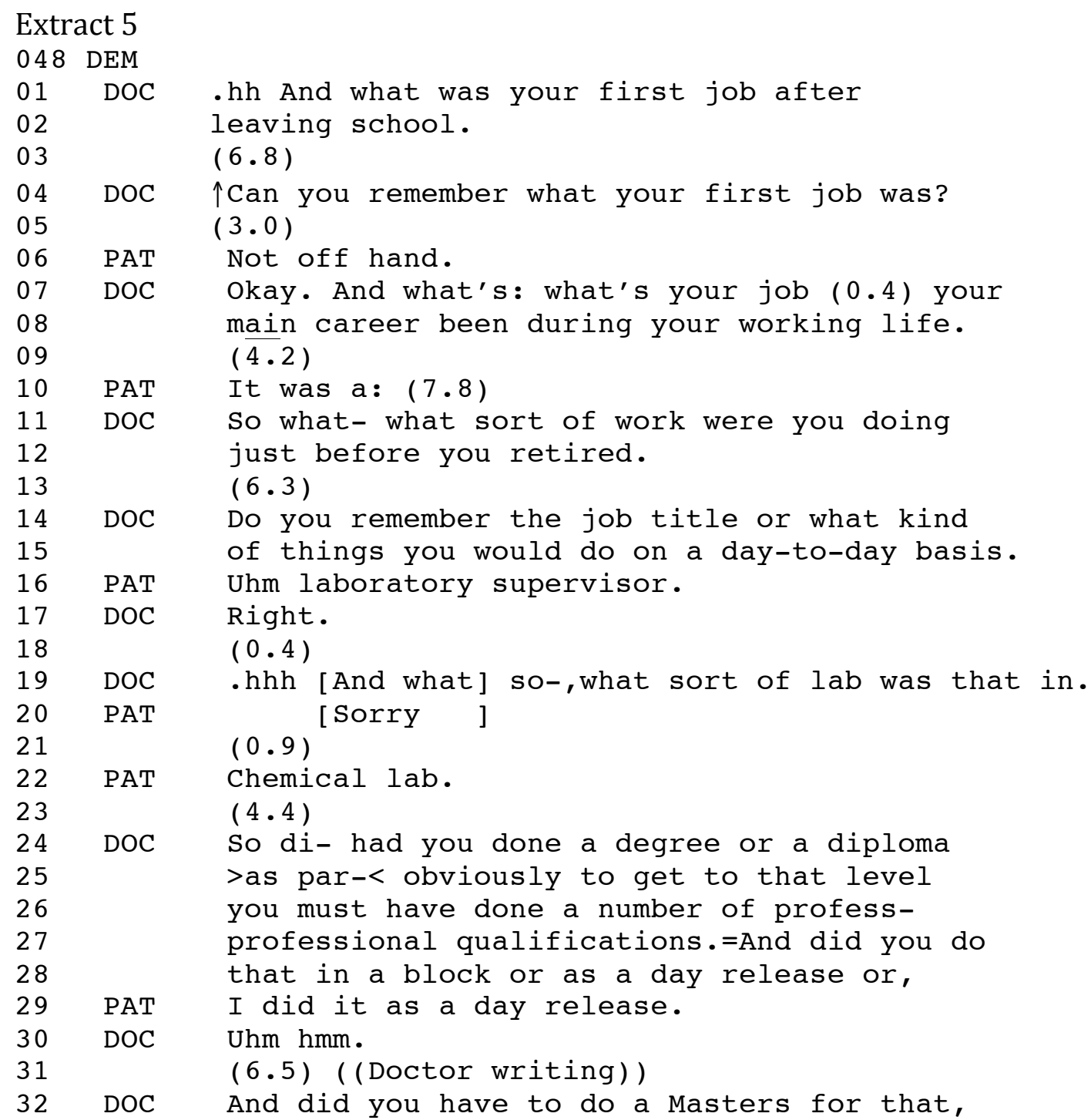




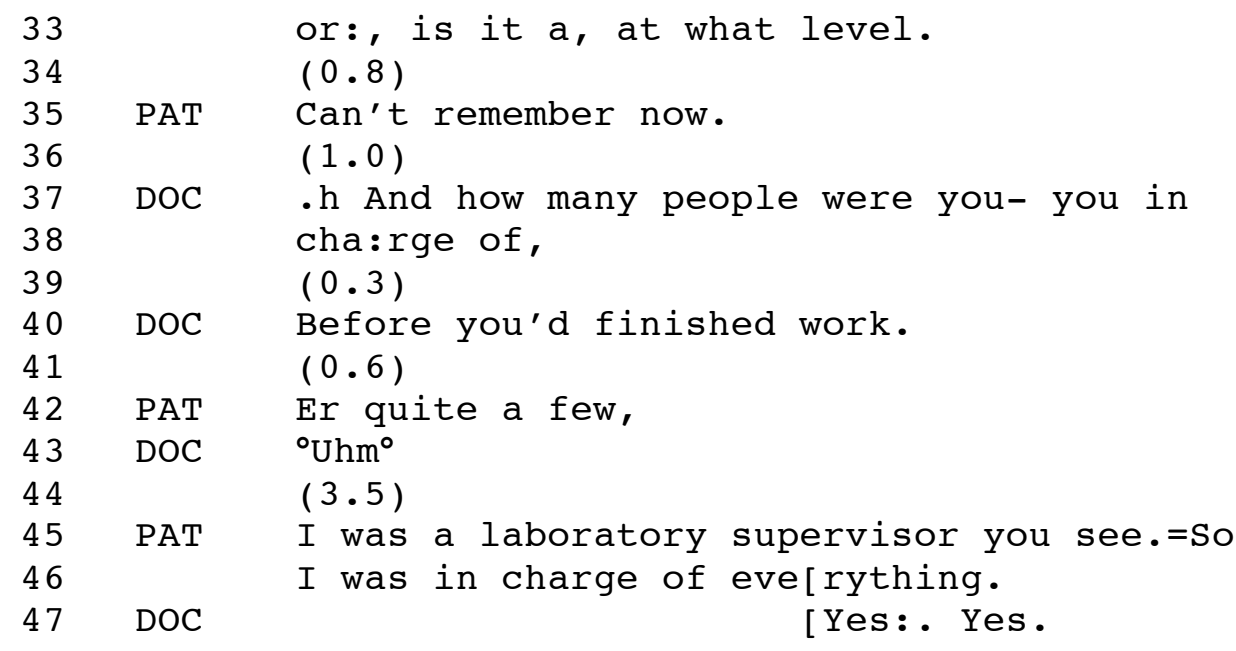

The patient told the neurologist twice within a few minutes that she was a laboratory supervisor (lines 16 and 45), once in response to a series of previously unanswered questions about her career and once in response to a question about how many staff she was in charge of. The second telling was produced with no preface orienting it as a repetition and is receipted by the neurologist with a multiple saying, 'Yes. Yes.' (Stivers, 2004) marking the prior as problematic due to its perseveration and revealing a disruption of cognitive functioning. The 'you see' (line 45) which forms part of the patients second time telling attends to the lack of specificity she gave in her previous answer of being in charge of 'quite a few' people (line 42). Being in a higher position as a 'supervisor', and indeed being 'in charge of everything' could explain why 'quite a few' is a legitimate answer in that she may have overseen a larger number of people. The point here is that patient's in these consultations who have dementia are often repetitive but do not mark their repetition. None of the patients with dementia used resources such as 'as I said' or 'like I say'. These features and displays of working memory (or lack thereof) in the interaction appear to be diagnostically significant and can contribute to the differentiation of diagnoses.

\section{Compound questions}

Neurologists questions during the consultations range from mono-topical, e.g. 'How old are you?' (extracts $1 \& 2$ ) or 'What was your first job after leaving school?' (Extract 5), or they may consist of multiple components (Extract 3) requiring the patient to produce several different responses to each of the multiple components. A patient's ability to answer all parts of these compound questions offers differential diagnostic potential. It has already been established (in Extract 3) that patients with FMD are able to respond to compound questions, often over an extended period of time and following detailed talk. Here is another example of an exchange involving the neurologist asking a compound question (this time constructed with three parts) and the patient with FMD responding relevantly to all three parts of the question.

\section{Extract 6 \\ 010 FMD \\ 01 DOC \\ 02

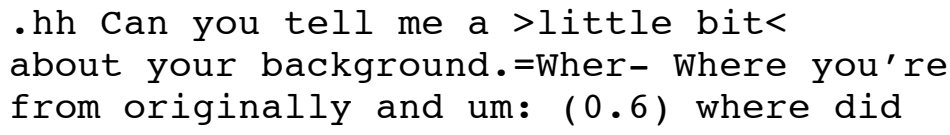




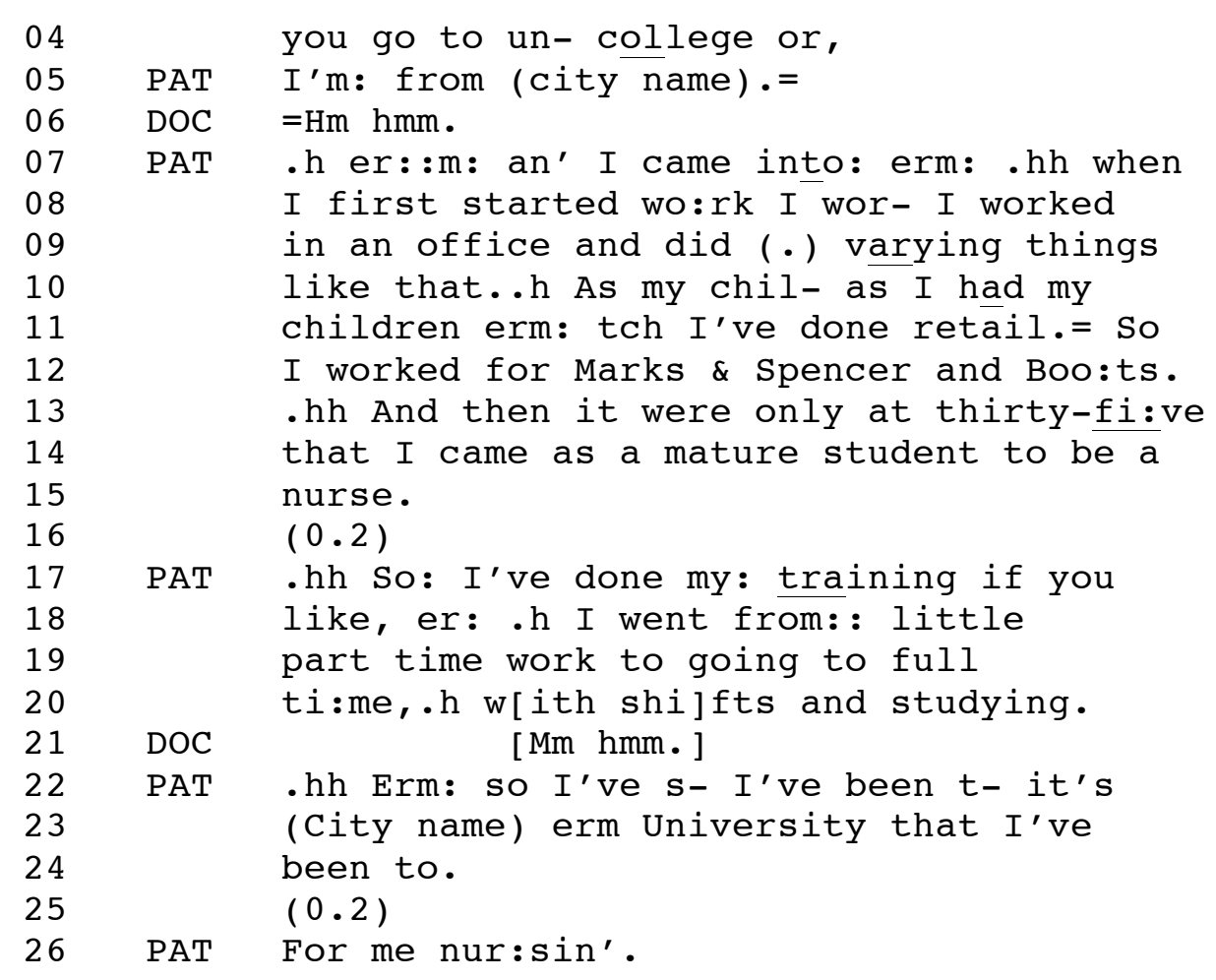

The patient recalls and is able to process and respond accurately to all parts of the neurologist's compound question - telling her where she was from originally (line 5), giving a bit of background about herself (lines 7-20) and where she went to university (line 23) - the three things the neurologist asked for. Her answer demonstrates that she is able to respond in detail to personal informationseeking questions, is able to display working memory in interaction and is able to process and respond to compound questions. These features are characteristic of individuals with FMD.

People with dementia frequently have difficulty comprehending questions, in addition to those they experience in recalling information; together these difficulties mean that conversational communication can be challenging for them. As a result, people with dementia often experience difficulty in answering all parts of a compound question (see Extract 7).

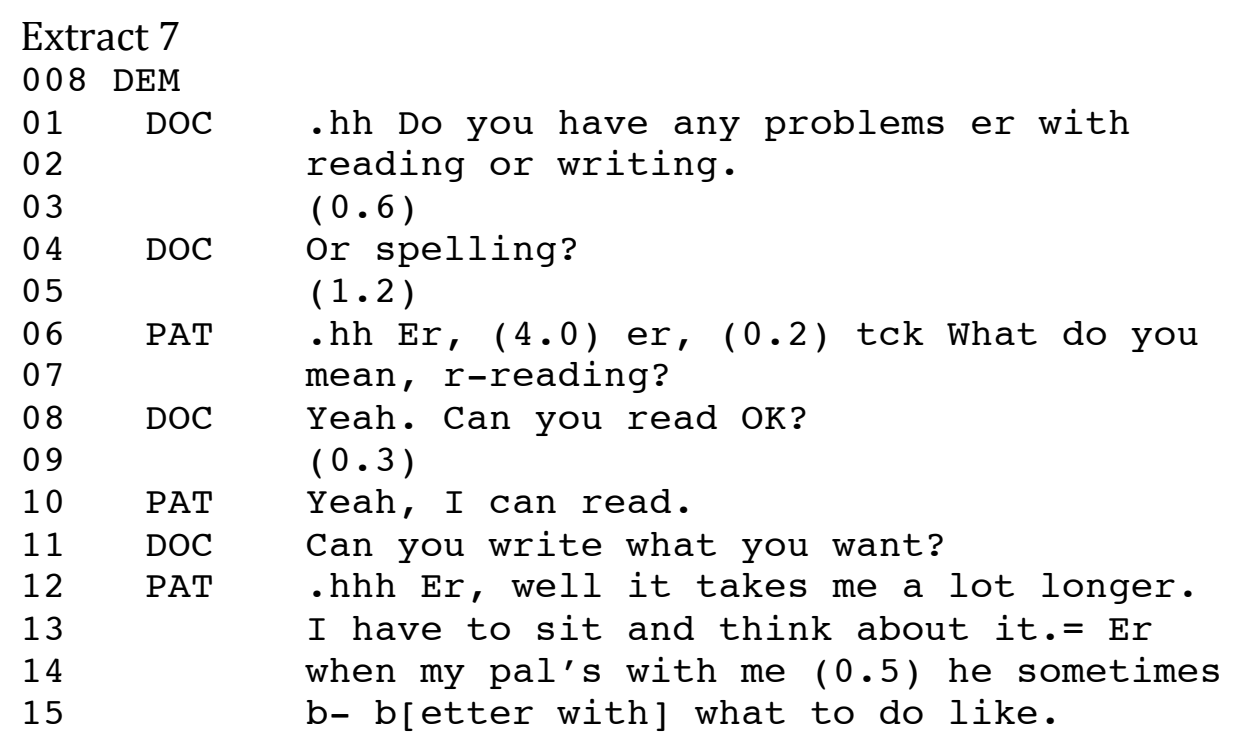




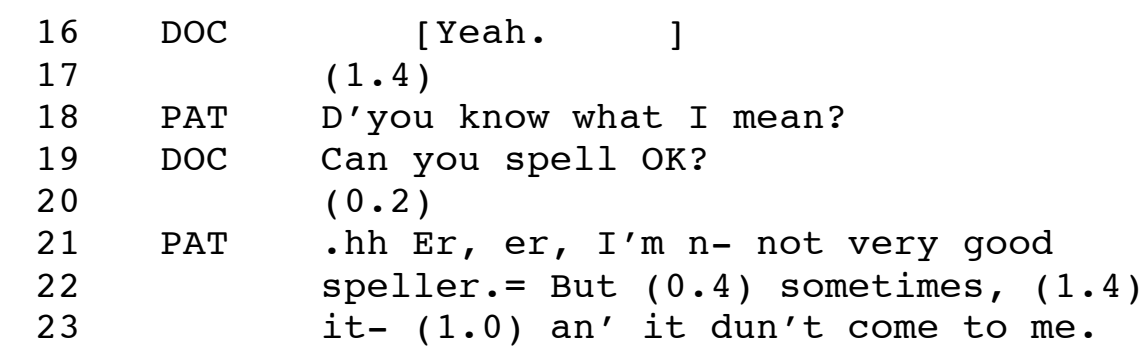

The patient is unable to respond to all three parts of this question and instead pursues clarification from the doctor (lines 6-7). The doctor prompts the patient by continuing to break the question down, asking each point individually, after which the patient responds. This suggests that the patient is unable to recall and process the three parts of the question simultaneously. The patient not only answers the questions with a relevant response when asked individually but he also displays an understanding of each of the functions through gestured actions. Such compound questions pose a greater difficulty for those with dementia then they do for people with FMD.

\section{Patient delays in responding}

There are a number of additional features that relate to the ones described above. Typically, in response to the neurologist's questions, people with dementia either do not respond (prompting further questioning from the neurologist, e.g. Extract 5, lines 1-5 and 11-15) or take longer to answer than people with FMD. In the sequences from the consultations with FMD patients in previous extracts it is apparent that patients answers contiguously, with no intervening delay in responding. This pattern of no delay appears in Extract 1 (lines 1-2 - responding to the question about age); Extract 3 (lines 5-6 responding to the neurologist's questions about the reason for the patient's visit to the clinic and what expectations they have); Extract 4 (lines 8-9 - the patient being asked to describe a typical migraine); and Extract 6 (lines 4-5 - responding to a request to background information). However, by contrast quite often the responses given by people with dementia are delayed (see Extract 5 lines 3, 5, 9, 21, 34, 41 and Extract 7 lines 3, 5, 9, 20). Often this delay is substantial, for example in Extract 5 (line 3) there is a delay of 6.8 seconds between the neurologist's initial question and their follow up questions (a total delay of 9.8 seconds until the patient produces a response). Delay in interaction is therefore a further differentiating feature between FMD patients and those with dementia.

\section{The elaboration of patient's accounts through detailing}

The detail people exhibit in their talk also has the potential to differentiate between the diagnoses. When people with FMD respond to the neurologist's questions, their responses consist of multiple and extended turns containing detailed examples and additional often-unsolicited information (see Extract 8).

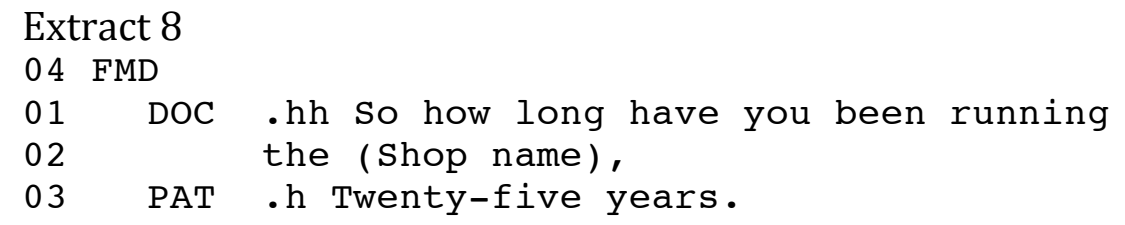




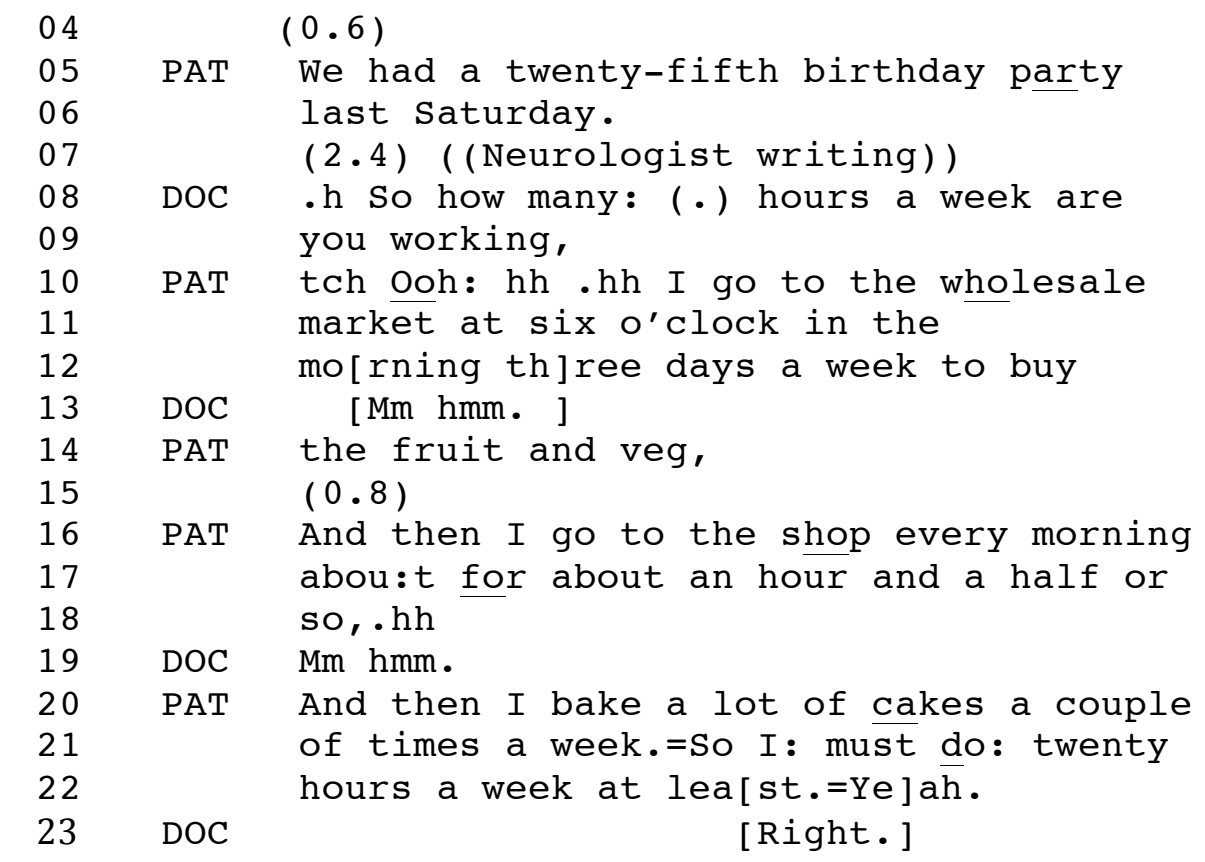

Here the patient answers each of the neurologist's questions (lines 1-2 and 8-9), her responses being elaborated over more than one turn. She introduces new information, which has not been solicited by the neurologist in her questions. Following the first question, 'So how long have you been running the (shop)' (lines 1-2), that patient's answer is contiguously, 'Twenty-five years' (line 3). She then volunteers more information about the celebration they had to mark the anniversary; detailing what day of this week this event took place (lines 5-6). An extended response was also produced following the neurologist's second question enquiring about how many hours a week the patient works (lines 8-9). Although an answer, 'Twenty hours a week at least' (lines 21-22) was given, this came after a detailed description of the patient's weekly activities, including what time she goes to the market ('six o'clock in the morning', lines 10-11) and what she purchases ('fruit and veg', line 14). This extract illustrates a recurrent pattern in the consultations with FMD patients in that their talk is detailed, and this detail is often unsolicited by the neurologist. Furthermore, volunteering this detailed information displays episodic memory capabilities in the interaction.

When patients with dementia respond to the neurologist's questions, their responses often consist of admissions of forgetfulness or lack of knowledge/understanding (often attesting to a lack of episodic memory), for example 'Can't remember now' and 'Not off hand' (Extract 5, lines 6 and 35), and below in Extract 9 (line 4) in which the patient admits to 'not entirely' being able to describe his understanding about why he is at the clinic. These, as well as other responses, are typically very short, consisting of only single utterance or single turn units. These lack specificity and detail and rarely volunteer any additional information that falls outside the requirement of the question. The patient with dementia in Extract 9 below exhibits delayed and undetailed interaction.

\section{Extract 9}

033 DEM

01 DOC Could you describe what's: What you 


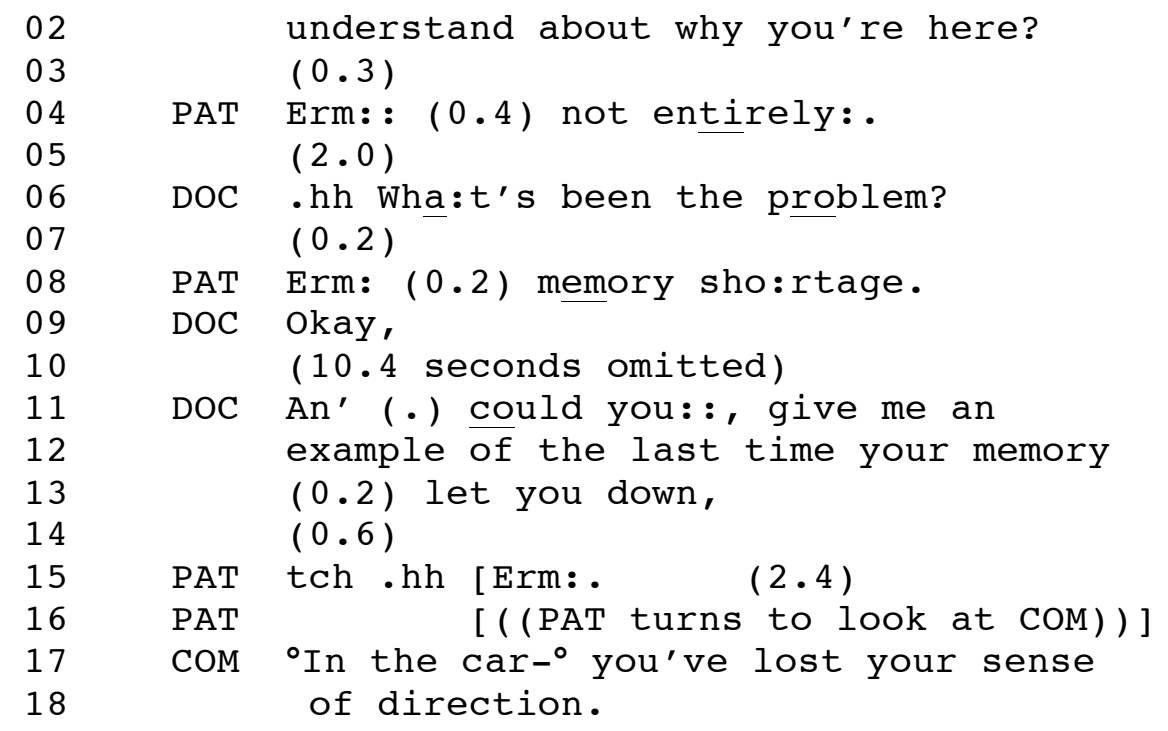

Following each of the neurologist's questions (lines 1-2, 6, 11-13) the patient delays responding (lines 3, 7 and 14). His responses lack any additional detail (of the kind seen in Extract 3, lines 6-24, Extract 6, lines 7-24 and Extract 8, lines 1022), and are short, often consisting of just two words as in lines 4 and 8. In response to the third question the patient's only response is 'Erm', before turning his head to seek help from his companion in answering the question. Although the head turning sign (Fukui, 2011) appears to be a recurrent pattern in these consultations and is a characteristic feature of the communicative practice of people with dementia, it is not the focus here. Instead it is important to note that the responses given people with dementia are delayed and undetailed, often leaving the detail to be provided by their companion (in this instance this appears in line 17). These divergent patterns in the content and delay of interaction contribute to the different conversational profiles.

\section{Discussion}

In this exploratory stage we have identified a number of interactional features that begin to form differential conversational profiles between people with dementia and those with other functional memory complaints.

The initial findings show that people with FMD are able to respond contiguously and in detail to questions, including those requesting personal information, often volunteering additional information (which is unsolicited). They can display working memory in interaction and engage in additional interactional work, marking self-repetitive talk using resources such as 'as I said'. In doing so they orient to a recollection that the information has been previously voiced and display an awareness of their repetition. They are also able to process and respond to compound questions. In our consultations we have observed distinct differences in the communicative practices of those with dementia, who are frequently unable produce accurate information about themselves such as how old they are or where they live. Their responses to questions are delayed, minimal (consisting of single utterances or singles turns) and undetailed. People with dementia regularly display a lack of working memory in interaction by repeating themselves, providing information that is unmarked and produced as if for the first time. They also struggle to transact compound questions. 
Taken independently these features may not hold significant diagnostic value but used collectively they have to potential to enable differential diagnosis based on communicative practices. As demonstrated in the seizure research (Reuber et al., 2009), conversational profiling has potential clinical applications, in this case in the differential diagnosis of dementia and functional memory disorders. Practitioners would need actively to listen for the interactional practices outlined in the profiles. Additionally this research and the resulting profiles could underpin an interactional toolkit to aid practitioners in designing their consultation to maximise diagnostic potential, for instance they may wish to design appropriate compound questions and listen for the response. This contravenes much of the standard communications training on 'effective communication', which uses the KISS principle - keep it short and simple (Manthorpe, Young \& Howells, 2011). However, there is a diagnostic benefit to 'conversational testing' that is perceived to be less stressful than the battery of neuropsychological examinations the patients experience during the process (Lai et al, 2008; Gibson \& Anderson, 2011).

The features identified here are likely to be an interactional reflection of the cognitive difficulties that may also be demonstrable by more detailed neuropsychological assessment exploring domains such as memory, attention/orientation, language and verbal fluency. The features described here highlight the functioning (or mal-functioning) of memory systems in interaction. As such an observational diagnostic tool based on our observations might help to reduce the requirement for expensive, time-consuming neuropsychological testing in people with clear evidence of dementia and functional memory disorder. This will speed up access to specialist investigations and treatment, especially in resource-limited settings. In view of the likelihood that in future GPs will play a greater role in the dementia 'process' (diagnosis, care and treatment of dementia patients), the approach to profiling suggested by this study may help to give GPs greater confidence in their screening decisions. Informal discussions with GPs indicate that they would welcome some means of assessing patients presenting with memory concerns in such a way as to help avoid recommending for expensive and upsetting neuropsychological testing and MRI scanning those for whom such tests are unnecessary.

This study describes initial observations, and at this relatively early stage of our research programme developing the use of conversational profiles as an auxiliary diagnostic method in the memory clinic we should discuss a number of limitations. The observation of sensitivity, specificity and inter-rater reliability of the identified interactional and linguistic diagnostic pointers will be essential before this approach is recommended as a diagnostic method. Previous research using conversational profiles in the differential diagnosis of epilepsy and psychogenic non-epileptic seizures (PNES) has demonstrated how the diagnostic potential of interactional and linguistic observations can be proven using a prospective multi-rater study design.It is also acknowledged here that both dementia and FMD are not homogenous categories and this pilot project does not offer an insight into the differentiating subtypes of dementia including Alzheimer's disease, fronto-temporal dementia, dementia with Lewy body and other Parkinsonian syndromes for example, as well as into the spectrum of functional memory complaints including those caused by both behavioural and cognitive difficulties. The heterogeneous nature of these subtypes makes any 
group studies difficult due to the variability in the nature of the associated cognitive and communicative impairments (Gardner, 1974; Bayles, 1985). However, common symptoms of each subtype can be identified, and indeed similarities between subtypes can be recognized. Further studies may explore the differential diagnosis between subtypes of both dementia and of FMD. Whilst the nature of our observations makes it relatively unlikely that they are dependent on the age or gender of patients, we should also replicate our observations in larger groups of patients before ruling out conversational effects of demographic factors on our findings

With government initiatives seeking better ways to screen for dementia and to improve the patient experience during this screening process, practitioners in both primary care and secondary services are looking for new approaches to meet these goals. Despite the limitations of this initial work, the interactional profiles described above have the potential to offer a method of assessment based on the patient's contribution to routine clinic conversations, and to provide inform clinical judgments made during history taking. Using 'conversation as assessment' could be of significant diagnostic value and provide a useful screening tool for dementia. The demonstration that their memory is functioning in interaction may provide helpful reassurance to patients with functional memory disorders (Stone, 2014).

\section{References}

Alzheimer's Society (2014). Dementia diagnosis rates. Available $>$ http://www.alzheimers.org.uk/site/scripts/documents_info.php?documentID $=2165<$

Bayles, K.A. (1985) Communication in dementia. In H. Ulatowska (Ed.), The aging brain (pp. 157-173). San Diego: College-Hill Press.

Blackburn, D.J., Wakefield, S., Shanks, M.F., Harkness, K., Reuber, M., Venneri, A. (2014). Memory difficulties are not always a sign of incipient dementia: A review of the possible causes of loss of memory efficiency. British Medical Bulletin,112, 71-81.

Blackburn, D.J., Bell, S.M., Wakefield, S., Harkness, K., Rittman, T., Rowe, J., Walpole, P., Reuber, M., Venneri, A. (2015). Changing face of the memory clinic in the UK. Postgraduate Medical Journal (under review).

Boustani, M., Callahan, C.M., Unverzagt, F.W., Austrom, M.G., Perkins, A.J., Fultz, B.A., Hui, S.L. Hendrie, H.C. (2005). Implementing a Screening and Diagnosis Program for Dementia in Primary Care. Journal of General Internal Medicine, 20, 572-577.

Department of Health (2012) Commissioning for Quality and Innovation (CQUIN) framework. Accessed 28th August 2013. Available >https://www.gov.uk/government/publications/using-the-commissioning-forquality-and-innovation-cquin-payment-framework-guidance-on-new-nationalgoals-for-2012-13<

Drew, P., Chatwin, J., \& Collins, S. (2001). Conversation analysis: A method for research into interactions between patients and health-care professionals. Health Expectations, 4, 58-70.

Drew, P. (2005). Conversation analysis. In K. L. Fitch, \& R. E. Sanders (Eds.), Handbook of language and social interaction (pp. 71-102). London, UK: Lawrence Erlbaum Associates Publishers.

Ekberg, K., McDermott, J., Moynihan, C., Brindle, L., Little, P. and Leydon, G.M. (2014). The role of helplines in cancer care: Intertwining emotional support with 
information or advice seeking needs. Journal of Psychosocial Oncology, 32, 359-

381.

Elsey, C., Drew, P., Jones, D., Blackburn, D., Wakefield, S, Harkness, K, Venneri, A., Reuber, M. (2014). Towards diagnostic conversational profiles of patients presenting with dementia or functional memory disorder to memory clinics. Patient Education \& Counselling. Under review.

Fukui, T., Yamazaki, T. \& Kinno, R. (2011). Can the 'head-turning sign' be a clinical marker of Alzheimer's disease? Dementia and Geriatric Cognitive Disorders Extra, 1, 310-317.

Gardner, H. (1974). The shattered mind: The person after brain dDamage. New York: Random House.

Gibson, A. \& Anderson, K. (2011). Difficult diagnoses: Family caregivers' experiences during and following the diagnostic process for dementia. American Journal of Alzheimer's disease and other dementias, 26, 212-217.

Heritage, J. \& Stivers, T (1999). Online commentary in acute medical visits: A method of shaping patient expectations. Social science \& medicine, 49, 1501-1517.

Heritage, J \& Maynard, D.W. (2006). Communication in medical care. Cambridge University Press, Cambridge.

Heritage, J. \& Robinson, J. (2006). The structure of patients' presenting concerns: Physicians' opening questions. Health Communication, 19, 89,-102.

Heritage, J., Robinson, J., Elliott, M., Veckett, M. \& Wilkes, M. (2007). Reducing patients' unmet concerns in primary care: The difference one word can make. Journal of General Internal Medicine,, 22, 1429-33.

Hesler, J., Bronner, M., Etgen, T., Ander, K.H., Forstl, H., Oppert, H. et al. (2014). Suitability of the 6 cite as a screening test for dementia in primary care patients. Journal of Aging and Mental Health, 18, 515-520.

Høgh, P., Waldermar, G., Knudsen, G.N., Bruhn, P., Mortensen, H., Wildschiødtz, G., Bech, R.A., Juhler, N., Paulson, O.B. (1999). A multidisciplinary memory clinic in a neurological setting: Diagnostic evaluation of 400 consecutive patients. European Journal of Neurology, 6, 279-288.,

Jefferson, G. (1983). Issues in the transcription of naturally-occurring talk: Caricature versus capturing pronunciational particulars. Tilburg papers in language and literature, Tilburg University, Tilburg. pp. 1-12.

Jefferson, G. (2004). Glossary of transcript symbols with an introduction. In G. H. Lerner (Ed.), Conversation analysis: Studies from the first generation (pp. 13-23). Philadelphia: John Benjamins.

Jones, D. (2012). Conversations with a person with Alzheimer's disease: A conversation analytic study. Unpublished PhD dissertation, University of York, York, UK.

Jones, D. (2013). A family living with Alzheimer's disease: The communicative challenges. Dementia: The International journal of social research and practice, September 18, 2013, doi:10.1177/1471301213502213.

Knopman, D.S., DeKosky, S.T., Cummings, L.L., Chui, H., Corey-Bloom, J., Relkin, N., Small, G.W., Miller, B. Stevens, J.C. (2001). Practice parameter: Diagnosis of dementia (an evidence-based review). Neurology, 59, 1143-1153.

Lai, J.M., Hawkins, K.A., Gross, C.P. \& Karlawish, J.H. (2008). Self-reported distress after cognitive testing in patients with Alzheimer's disease. Journal of Gerontology Series A, 63, 855-859.

Larner, A.J., (2014). Impact of the national dementia strategy in a neurology led memory clinic: 5-year data. Clinical Medicine, 14, 216. 
Manthorpe, C., Young, T., Howells, D. (2011). DEMTEC: Dementia toolkit for effective communication. Available at >http://www.demtalk.org.uk/wpcontent/uploads/2012/11/DemTalk_Full_HealthCareProfessionals.pdf<

NHS direct enhanced service (2013). Facilitating timely diagnosis and support for people with dementia. Available $>$ http://www.england.nhs.uk/wpcontent/uploads/2013/03/ess-dementia.pdf<

Reuber, M., Monzoni, C., Sharrack, B. \& Plug, L (2009). Using interactional and linguistic analysis to distinguish between epileptic and psychogenic nonepileptic seizures: A prospective, blinded multirater study. Epilepsy \& Behavior, 16, 139-144

Robson, C., Drew. P., Walker, T. \& Reuber, M. (2012). Catastrophising and normalising in patient's accounts of their seizure expriences. Seizure, 21, 795-801.

Royal College of Psychiatrists (2013). English national memory clinic audit report. Available >http://www.rcpsych.ac.uk/pdf/English\%20National\%20Memory\%20Clinics\% 20Audit\%20Report\%202013.pdf<

Schmidtke, K., Pohlmann, S. \& Metternich, B (2008). The syndrome of functional memory disorder: Definition, etiology, and natural course. American Journal of Geriatric Psychiatry, 16, 981-988.

Schmidtke, K. \& Metternich, B. (2009). Validation of two inventories for the diagnosis and monitoring of functional memory disorder. Journal of Psychosomatic Research, 67, 245-251.

Schwabe, M., Howell, S.J. \& Reuber, M. (2007). Differential diagnosis of seizure disorders: A conversation analytic approach. Social Science \& Medicine, 65, 712-724.

Sidnell, J. (2010). Conversation analysis: An introduction. Sussex, UK: Wiley-Blackwell.

Stivers, T (2002). Participating in decisions about treatment: overt parent pressure for antibiotic medication in pediatric encounters. Social Science \& Medicine, 54, 1111-1130.

Stivers, T. (2004). "No no no" and other types of multiple sayings in social interaction. Human Communication Research, 30, 260-293.

Stone, J. (2014). Functional neurological disorders: the neurological assessment as treatment. Neurophysiologie Clinique, 44, 363-373.

Verhey, F.R., Jolles, J., Ponds, R.W., Vreeling, F.W. (1993). Psychiatric disorders in patients of a memory outpatient clinic. NedTijdschr Geneeskd, 137, 1054-1058.

\section{Appendix 1}

\section{Transcription symbols}

DOC $/$ PAT $\quad$ Speaker labels $(\mathrm{DOC}=$ Doctor $/$ Neurologist; PAT $=$ Patient; $\mathrm{COM}$ Companion)

$=\quad$ Links talk produced in close temporal proximity (latched talk)

$>\quad$ Talk between symbols is rushed or compressed

$\therefore \quad$ Encloses talk which is produced quietly

underline Underlining marks emphasis of some kind

CAPS Words or parts of words spoken loudly marked in capital letters

s::::: $\quad$ Sustained or stretched sound; the more colons, the longer the sound

. ? , Stop indicates falling intonation; a question mark indicates rising

intonation

word

over a word; a comma indicates a slight rising intonation at the end of

.hhh

Inbreath, the number of ' $h$ 's representing the length of the inbreath 
hhh. Outbreath, the number of 'h's representing the length of the outbreath [ ] Encloses talk in overlap i.e. when more than one speaker is speaking (word) Parentheses indicate transcriber doubt

(this/that) Alternative hearings

((description)) Description of what can be heard, rather than transcription e.g.

((shuffling

papers)

cu- $\quad$ Cut-off word or sound

(0.6) Silence in seconds

(.) Silence of less than two tenths of a second

$\wedge$ or - Indicates marked pitch rise

- Indicates marked fall in pitch

(hhenhh) Indicates laughter while speaking (aspiration) 